\title{
Lung metastases from colorectal cancer: a multidisciplinary approach and role of local treatment: a narrative review
}

\author{
Ka Lun Mak, Michael Kuan Yew Hsin \\ Department of Cardiothoracic Surgery, Queen Mary Hospital, Hong Kong, China \\ Contributions: (I) Conception and design: Both authors; (II) Administrative support: Both authors; (III) Provision of study materials or patients: MKY \\ Hsin; (IV) Collection and assembly of data: KL Mak; (V) Data analysis and interpretation: Both authors; (VI) Manuscript writing: Both authors; (VII) \\ Final approval of manuscript: Both authors. \\ Correspondence to: Ka Lun Mak. Department of Cardiothoracic Surgery, Queen Mary Hospital, Hong Kong, China. Email: klmakmak1020@gmail.com.
}

\begin{abstract}
Objective: To review current available options of local treatment for colorectal lung metastases.
Background: Colorectal cancer is one of the leading malignancies worldwide. Despite advances in screening policy and early surgical treatment, a significant number of patients are suffering from colorectal metastatic disease, including the lung. Local treatment for pulmonary metastatic colorectal cancer has made significant progress in the last few decades. Survival benefit and procedure related morbidity are widely studied.

Methods: PubMed database is searched for articles related to local treatment of colorectal lung metastases including pulmonary metastasectomy, radiofrequency ablation, radiotherapy, isolated lung perfusion.

Conclusion: Local treatment for colorectal lung metastases is widely prescribed for purported survival benefit, although evidence is based on retrospective studies only. With advances in technique and technology, approaches such as minimally invasive thoracoscopic surgery and percutaneous radiofrequency ablation can minimize trauma and procedure related morbidity. New modalities of radiotherapy like stereotactic body radiation therapy (SBRT) can reduce radiation related toxicity to surrounding structures. Isolated lung perfusion can maximize the dose of chemotherapeutic agents that can be safely delivered to the lung parenchyma; however, this is at the expense of significant associated morbidity. The role of local treatment to colorectal lung metastases needs further randomized controlled trials to define the survival benefit. Multidisciplinary meetings, involving oncologists, thoracic surgeons and interventional radiologists, are advisable before offering local treatment to patients with colorectal lung metastases.
\end{abstract}

Keywords: Local treatment; colorectal lung metastases; multidisciplinary approach

Received: 05 July 2021; Accepted: 15 March 2022; Published: 30 September 2022.

doi: 10.21037/asj-21-59

View this article at: https://dx.doi.org/10.21037/asj-21-59

\section{Introduction}

Colorectal cancer is a common malignancy causing morbidity and mortality. Despite advances in screening and early surgical treatment of colorectal primary tumor, metastases to different organs, including the liver and lung, is still prevalent. Treatment options for colorectal lung metastases, including systemic chemotherapy, targeted therapy, radiotherapy, surgical resection of lung metastases, tumor ablation, have been studied widely in the hope of improving patient survival. This review article will focus on local treatment of colorectal lung metastases. We present the following article in accordance with the Narrative Review reporting checklist (available at https:// asj.amegroups.com/article/view/10.21037/asj-21-59/rc).

\section{Methods}

A review of literature was performed in PubMed database with key word "colorectal lung metastases", "pulmonary 
metastasectomy", "radiotherapy", "radiofrequency ablation" and "isolated lung perfusion" is performed. Meta-analysis, randomized controlled trial, retrospective studies, case reports related to outcome of local treatment of colorectal pulmonary metastases are included for review. Non-English written articles and review articles are excluded.

\section{Discussion}

\section{Pulmonary metastasectomy}

Surgical resection of colorectal lung metastases is a frequently performed procedure around the world. According to the different national registry data and retrospective studies, 5-year overall survival of pulmonary metastasectomy for colorectal cancer is around $40 \%$ to $70 \%$ (1-10). The evidence supporting pulmonary metastasectomy for survival is largely based on retrospective studies and registry data, which are inevitably limited by selection bias. The patient demographics and treatment protocols are heterogenous from study to study. According to the International Registry of Lung Metastases in 1997, the 5 -year survival of patients with colorectal lung metastases without resection was around $10 \%$ despite systemic treatment (11). With recent advances of chemotherapy regimen and targeted therapy, patients with systemic treatment are having better survival and quality of life. In the year 2020, Treasure analyzed the data from the incomplete randomized controlled trial Pulmonary Metastasectomy in Colorectal Cancer (PulMiCC) and showed that in patients with pulmonary metastases who did not undergo resection received systemic treatment, a 5 -year survival of $29 \%$ was achieved. For patients with pulmonary metastasectomy performed, 5 -year survival is $38 \%$ but the sample size is too small to draw conclusion $(12,13)$. Although the study was terminated because of poor patient recruitment, this is the most contemporary outcome data on patient with colorectal lung metastases. There are prospective study and national registry data suggesting that pulmonary metastasectomy confers no benefit in survival and patient reported quality of life (14-16). Survival benefits of pulmonary metastasectomy for colorectal lung metastases should be further studied in randomized controlled trials with adequate power.

\section{Indication and patient selection of pulmonary metastasectomy}

Lung metastases are usually indolent and asymptomatic. The goal of pulmonary metastasectomy is to improve patient survival. It is paramount to balance the risks and benefits of pulmonary metastasectomy, and judicious patient selection can improve the outcome of pulmonary metastasectomy. According to the International Registry of Lung Metastasis (11), factors to consider when offering pulmonary metastasectomy should include tumor resectability, operability of the patient with particular attention to the lung function, whether control of the primary tumor has been achieved, the lack of alternative treatment and the absence of synchronous extra-thoracic disease.

In our center, all patients referred to us for pulmonary metastasectomy are properly worked up with positron emission tomography-computerized tomography (PET-CT) scan and pulmonary function test. Patients' performance status and co-morbidities are assessed by thoracic surgeon. These patients are discussed in multidisciplinary meeting with oncologist case by case. Pulmonary metastasectomy will be considered in patients with no extra-thoracic metastases, good performance status, pulmonary metastases which can be resected completely, predictive postoperative forced expiratory volume and diffusing capacity of carbon monoxide greater than $40 \%$.

Retrospective studies and case series have been performed to identify factors associated with better survival following pulmonary metastasectomy. A longer disease free interval (17-19), a lower carcinoembryonic antigen (CEA) level before pulmonary metastasectomy $(20,21)$, a smaller number of pulmonary metastases $(18,22,23)$ are features that have been associated with better survival after pulmonary metastasectomy identified in retrospective studies. A metaanalysis of retrospective studies was performed in 2012 and showed that a disease-free interval of less than 36 months, a pre-thoracotomy CEA level greater than $5 \mathrm{ng} / \mathrm{mL}$, and more than one metastatic lesion, are factors associated with worse survival in pulmonary metastasectomy. A prognostic model was designed to assess the risk of pulmonary metastasectomy. If a patient exhibited all 3 risk factors, the 5 -year survival was $26.8 \%$ while it increased to $68.2 \%$ in a patient with zero or only one risk factor $(\mathrm{P}<0.001)(24)$.

Circulating tumor cells (CTCs) have been well studied as biomarkers for prognosis of patients with colorectal cancers. In a retrospective study performed in Germany, if patients had circulating tumor cells in the pulmonary vein detected during pulmonary metastasectomy, this was associated with increased thoracic lymph node metastases (25). Another retrospective study performed in Japan showed that the presence of circulating tumor cells in peripheral blood during metastasectomy was associated with worse 
overall and disease-free survival (26). Both studies are retrospective studies and the role of circulating tumor cells in the decision making for pulmonary metastasectomy is still under investigation.

Primary tumor location has been investigated as a prognostic marker for pulmonary metastasectomy. According to a retrospective study performed by MD Anderson Pulmonary Metastasectomy Study Group, patients with left colon cancer were associated with better overall survival after pulmonary metastasectomy when compared with patients with right colon cancer and rectal cancer (27). Another retrospective study performed in Germany also showed similar findings (28).

However, there is significant heterogeneity among these studies in terms of patient demographics, follow up protocol and adjuvant chemotherapy protocol, and extrapolation from these studies needs to be done with caution.

A prior history of colorectal liver metastases was associated with worse prognosis in patients with pulmonary metastasectomy performed as reported in meta-analysis and retrospective studies (29-32). Nevertheless, for patients with previous colorectal liver metastases, pulmonary metastasectomy was associated with better survival in selected patients with long disease-free interval, normal carcinoembryonic antigen level, fewer tumor nodules and absence of mediastinal lymph node involvement (33-47).

The molecular status of colorectal lung metastases also has been studied in relation to survival after pulmonary metastasectomy. Survival in patients after pulmonary metastasectomy for colorectal lung metastases with tumors harboring RAS, BRAF and TP53 mutations were found to be worse than patients with wild type of RAS, BRAF and TP53 gene (48-50). On the other hand, APC gene and low expression of RNA-binding motif protein 3 expression were associated with better survival after pulmonary metastasectomy (51). Tumor biology appears to play a significant role in the survival of colorectal cancer (CRC) patients with metastatic disease.

In selected patients who developed pulmonary recurrence after pulmonary metastasectomy, repeated pulmonary metastasectomy may have survival benefit (52-55). Advanced age, male sex, increasing size and number of pulmonary metastatic nodules, high pre-thoracotomy carcinoembryonic antigen level, mediastinal lymph node involvement, high grade primary tumor, previous liver metastases were factors associated with worse survival (56-61). Careful patient selection is appropriate before offering repeated pulmonary metastasectomy to patients with pulmonary recurrence.

\section{Chemotherapy in patient with pulmonary metastasectomy}

With advances in systemic chemotherapy, aggressive multimodality treatment for colorectal lung metastases has been the focus of study in retrospective series (62). Aggressive multimodality treatment includes systemic chemotherapy, radical resection of primary colorectal cancer, and hepatic and pulmonary metastasectomy. In selected patients, aggressive multimodality treatment was associated with improved survival when compared with patients without perioperative chemotherapy. The reduction in mortality risk was greatest in patients receiving colorectal radical resection, chemotherapy and liver/lung resection (63).

The impact of chemotherapy, whether it is given before and after pulmonary metastasectomy, has been reported in different retrospective studies, and both strategies have been associated with improved disease-free survival by 6 to 20 months in the chemotherapy group (64-66). But in 2019 , there is a retrospective study with propensity score matching performed by Imanishi et al. suggesting that adjuvant chemotherapy after curative resection of lung limited metastases showed no survival benefit. Further randomized controlled trial is needed to define the survival benefit from adjuvant chemotherapy.

Amongst the chemotherapeutic agents for preoperative chemotherapy, oxaliplatin-based therapy was associated with improved OS when compared with irinotecan, capecitabine, or alternate regimen (67). No comparative study has been reported to study the timing of chemotherapy relative to pulmonary metastasectomy.

Patients who were most likely to benefit most from systemic chemotherapy were those with high value of preoperative CEA, hypermetabolism on the PET CT scan, previous extra-thoracic resected metastasis, and short ( $<12$ months) DFI, all of which were features associated with increased risks of disease recurrence (68).

Further prospective studies are needed to study the survival benefit and timing of systemic chemotherapy in selected patient undergoing pulmonary metastasectomy (53).

\section{Approaches to pulmonary metastasectomy (thoracotomy or video assisted thoracoscopic surgery or trans-diaphragmatic approaches)}

Video-assisted thoracoscopic surgery, thoracotomy and 
median sternotomy are commonly performed surgical approaches for pulmonary metastasectomy. The best approach for pulmonary metastasectomy remains controversial. Both retrospective and prospective studies suggested thoracotomy had advantages over video assisted thoracoscopic surgery because non-imaged tumor nodules could be detected by bimanual palpation during thoracotomy (69-71). With advances in the technology of computed tomography and improved imaging, recent large retrospective comparative studies and meta-analysis of observational studies showed clinical outcome of video assisted thoracoscopic surgery was comparable to thoracotomy. There was no difference in ipsilateral recurrence and disease-free survival. Overall survival was better in patients who underwent VATS approach (72-77). There is no randomized controlled trial to compare the oncological outcome between VATS and thoracotomy approach.

In highly selected groups of patients, transdiaphragmatic approach has been reported where pulmonary metastasectomy was performed in the same setting as the resection of the colorectal primary or hepatic metastasis. This has the advantage of avoiding a separate operation requiring general anesthesia. However, in the published reports, the number of patients who received this approach was small and no comparative study was performed to establish the clinical or oncological benefit of this approach (78-80).

\section{Extent of resection (anatomical resection or not)}

Sub-lobar resection for colorectal lung metastases should be performed in a manner which can preserve as much respiratory function as possible while adhering to the principle of resection which is to obtain a clear margin. Retrospective studies showed that higher local recurrence occurred in patients where the resection margin was involved (81). According to Welter et al., $7 \mathrm{~mm}$ margin is needed to remove satellite tumor cells and floating cancer cell clusters around the pulmonary metastases (82). Wedge resection, segmentectomy and lobectomy have been reported in the literature for pulmonary metastasectomy $(83,84)$. Pneumonectomy for colorectal lung metastases with survival in terms of years has been reported also $(85,86)$ but it is considered too aggressive for patients with systemic metastatic disease and this is not recommended by the European Society of Thoracic Surgeons (87). In our center, wedge resection with margin greater than $1 \mathrm{~cm}$ is performed for pulmonary metastasectomy if possible. Lobectomy will be performed if wedge resection cannot provide adequate margin. Patients are counselled during consent process that there is a possibility of primary lung cancer. Completion lobectomy is performed if histology showed primary lung cancer instead of colorectal pulmonary metastases.

Wedge resection of colorectal lung metastases can be performed with surgical staplers, laser resection or the cutand-sew technique. The result of pulmonary metastasectomy with laser is a relatively new technique with encouraging results according to retrospective comparative studies. In patients who underwent laser assisted surgery for metastasectomy, there was an association with improved survival, while the rates of complications including atrial fibrillation, pneumonia, prolonged chest tube placement and empyema were not increased compared to patients who underwent non-laser resection. Laser assisted surgery can minimize tissue damage and preserve respiratory function according to an animal study (88), and complete resection of all the pulmonary metastases was possible in a retrospective clinical series in patients who had adequate lung function (89).

A retrospective study showed that patients who had segmentectomy for pulmonary metastases harboring RAS mutation had a better overall survival and longer time to pulmonary recurrence when compared with patients undergoing wedge resection. But in patients with wild type RAS, the overall survival and time to pulmonary recurrence between segmentectomy group and wedge resection group was similar (90). Genetic analysis showed that pulmonary metastases and colorectal primary usually shared the same genetic RAS mutation and pulmonary metastases was common in patient with RAS mutation (91). Anatomical resection for pulmonary metastasectomy should be considered if the primary tumor harbored the RAS mutation. Tissue diagnosis before pulmonary metastasectomy for genetic status is not needed since high concordance between colorectal primary and colorectal pulmonary metastases.

\section{The role of mediastinal lymph node sampling}

Mediastinal lymph node involvement of colorectal cancer was associated with worse survival when compared with patients who did not (92-94). Although mediastinal lymph node dissection could not improve the survival of patients with mediastinal lymph node metastases from colorectal cancer (95), mediastinal lymph node sampling or dissection during pulmonary metastasectomy could provide important prognostic information. The sensitivity of positron emission tomography detecting mediastinal lymph node metastases 
was only $35 \%$ (95). The location of lymph node involvement, be it hilar or mediastinal, did not affect survival (96).

The European Society of Thoracic Surgeons advocates systematic lymph node sampling or dissection during pulmonary metastasectomy with curative intent (87).

\section{Ablation of pulmonary metastases}

Since the application of radiofrequency ablation in the treatment of primary lung cancer in 2000, ablative therapy of colorectal lung metastases has been studied also. A large case series in Japan showed the 5-year survival of patients treated with percutaneous radiofrequency ablation of colorectal lung metastases was similar to pulmonary metastasectomy (97). Also, radiofrequency ablation is technically less demanding, and can be performed regardless of whether there has been any previous thoracic surgery procedures, is associated with less pain and does not require a general anesthesia. However radiofrequency ablation may cause complications including pneumothorax (98), pleural effusion, abscess (99), bronchopleural fistula and injury to nerves (100).

Radiofrequency ablation of colorectal lung metastases is limited by the size of the tumor. The risk of local recurrence increases with the size of the lung metastases (97). No randomized controlled trial has been performed to compare surgery and radiofrequency ablation. Currently, radiofrequency ablation of colorectal lung metastases is reserved for patients with high general anesthetic risks who are not fit for operation.

\section{Stereotactic body radiotherapy to pulmonary metastases}

Stereotactic body radiotherapy (SBRT) is emerging as an alternative modality of local control therapy for colorectal lung metastases. It is offered to patients with suboptimal lung function or high surgical risks who are not fit for pulmonary metastasectomy. Although colorectal lung metastases are more radio-resistant when compared to lung metastases from other primaries (101), a meta-analysis showed that patients receiving SBRT with escalated doses for colorectal lung metastases had improved local control and overall survival with minimal toxicity (102). The reported rates of grade 3 toxicity is less than $10 \%$ and in most series less than $5 \%$; grade 4 or greater toxicity was rare with no cases documented in the reports (103-105).

Retrospective study by Nelson et al. showed that 2-year risk of local recurrence after SBRT (29.4\%) is higher than that after wedge resection (14.1\%) for colorectal lung metastases (106). But this retrospective study is limited by selection bias and the relationship between local recurrence and survival is not well defined. Further randomized controlled trial is needed to be performed to establish the relationship between local control and survival.

\section{In vivo isolated lung perfusion}

With the experience of isolated limb perfusion for melanoma and soft tissue sarcoma (107), in vivo isolated lung perfusion has been developed to deliver higher doses of chemotherapy to pulmonary tissue $(108,109)$. Pulmonary recurrence after pulmonary metastasectomy is common, up to $60 \%$ (108) according to retrospective studies. The theory of micro-metastases in pulmonary tissue has been postulated to account for this high recurrence. Isolated lung perfusion theoretically can deliver much higher doses of chemotherapy to the pulmonary tissue, while avoiding the dose limiting toxicity from systemic chemotherapy.

Animal experimental study has shown the safety of isolated lung perfusion (110). Nevertheless, the clinical use of isolated lung perfusion is not yet established, and this is an area which is still under active investigation. The morbidity related to isolated lung perfusion is not insignificant- thoracotomy is required to allow access to control the major pulmonary vessels. The benefit of in vivo isolated lung perfusion needs to be established with larger clinical trials.

\section{Summary}

Local treatments for colorectal lung metastases are advancing rapidly but the survival benefits from them remain to be determined. Even though local treatments for colorectal lung metastases are mostly safe with the advances in technology, they are not free from procedure related mortality or morbidity. Large randomized controlled trials are needed to guide our future management of colorectal lung metastases.

\section{Acknowledgments}

Funding: None.

\section{Footnote}

Provenance and Peer Review: This article was commissioned 
by the Guest Editors (Davide Tosi, Alessandro Palleschi and Paolo Mendogni) for the series "Management and Treatment of Lung Metastases" published in AME Surgical fournal. The article has undergone external peer review.

Reporting Checklist: The authors have completed the Narrative Review reporting checklist. Available at https:// asj.amegroups.com/article/view/10.21037/asj-21-59/rc

Peer Review File: Available at https://asj.amegroups.com/ article/view/10.21037/asj-21-59/prf

Conflicts of Interest: Both authors have completed the ICMJE uniform disclosure form (available at https://asj.amegroups. com/article/view/10.21037/asj-21-59/coif). The series "Management and Treatment of Lung Metastases" was commissioned by the editorial office without any funding or sponsorship. The authors have no other conflicts of interest to declare.

Ethical Statement: The authors are accountable for all aspects of the work in ensuring that questions related to the accuracy or integrity of any part of the work are appropriately investigated and resolved.

Open Access Statement: This is an Open Access article distributed in accordance with the Creative Commons Attribution-NonCommercial-NoDerivs 4.0 International License (CC BY-NC-ND 4.0), which permits the noncommercial replication and distribution of the article with the strict proviso that no changes or edits are made and the original work is properly cited (including links to both the formal publication through the relevant DOI and the license). See: https://creativecommons.org/licenses/by-nc-nd/4.0/.

\section{References}

1. McCormack PM, Burt ME, Bains MS, et al. Lung resection for colorectal metastases. 10-year results. Arch Surg 1992;127:1403-6.

2. Hunt SL, McKay A, Kelly LM, et al. A case series of pulmonary resection for metastatic colorectal cancer in a UK regional thoracic center. Future Oncol 2015;11:35-6.

3. Suzuki H, Kiyoshima M, Kitahara M, et al. Long-term outcomes after surgical resection of pulmonary metastases from colorectal cancer. Ann Thorac Surg 2015;99:435-40.

4. Guerrera F, Mossetti C, Ceccarelli M, et al. Surgery of colorectal cancer lung metastases: analysis of survival, recurrence and re-surgery. J Thorac Dis 2016;8:1764-71.

5. Al-Ameri M, Persson M, Bergman P, et al. Long-term survival after surgery for pulmonary metastases from colorectal cancer: an observational cohort study. J Thorac Dis 2017;9:4358-65.

6. Dudek W, Schreiner W, Hohenberger W, et al. FortyTwo Years' Experience with Pulmonary Resections of Metastases from Colorectal Cancer. Thorac Cardiovasc Surg 2017;65:560-6.

7. Sponholz S, Schirren M, Oguzhan S, et al. Morbidity, mortality, and survival in elderly patients undergoing pulmonary metastasectomy for colorectal cancer. Int J Colorectal Dis 2018;33:1401-9.

8. Oweira H, Mehrabi A, Reissfelder C, et al. A Real-World, Population-Based Analysis of the Outcomes of Colorectal Cancer Patients with Isolated Synchronous Liver or Lung Metastases Treated with Metastasectomy. World J Surg 2020;44:1604-11.

9. Yu WS, Bae MK, Choi JK, et al. Pulmonary Metastasectomy in Colorectal Cancer: A Population-Based Retrospective Cohort Study Using the Korean National Health Insurance Database. Cancer Res Treat 2021. [Epub ahead of print]. doi: 10.4143/crt.2020.1213.

10. Ratnayake CBB, Wells CI, Atherton P, et al. Meta-analysis of survival outcomes following surgical and non surgical treatments for colorectal cancer metastasis to the lung. ANZ J Surg 2021;91:255-63.

11. Pastorino U, Buyse M, Friedel G, et al. Long-term results of lung metastasectomy: prognostic analyses based on 5206 cases. J Thorac Cardiovasc Surg 1997;113:37-49.

12. Treasure T, Farewell V, Macbeth F, et al. Pulmonary Metastasectomy versus Continued Active Monitoring in Colorectal Cancer (PulMiCC): a multicentre randomised clinical trial. Trials 2019;20:718.

13. Milosevic M, Edwards J, Tsang D, et al. Pulmonary Metastasectomy in Colorectal Cancer: updated analysis of 93 randomized patients - control survival is much better than previously assumed. Colorectal Dis 2020;22:1314-24.

14. Brew-Graves C, Farewell V, Monson K, et al. Pulmonary metastasectomy in colorectal cancer: health utility scores by EQ-5D-3L in a randomized controlled trial show no benefit from lung metastasectomy. Colorectal Dis 2021;23:200-5.

15. Treasure T, Farewell V, Macbeth F, et al. The Pulmonary Metastasectomy in Colorectal Cancer cohort study: Analysis of case selection, risk factors and survival in a prospective observational study of 512 patients. Colorectal Dis 2021;23:1793-803. 
16. Siebenhüner AR, Güller U, Warschkow R. Populationbased SEER analysis of survival in colorectal cancer patients with or without resection of lung and liver metastases. BMC Cancer 2020;20:246.

17. Koga R, Yamamoto J, Saiura A, et al. Surgical resection of pulmonary metastases from colorectal cancer: Four favourable prognostic factors. Jpn J Clin Oncol 2006;36:643-8.

18. Borasio P, Gisabella M, Billé A, et al. Role of surgical resection in colorectal lung metastases: analysis of 137 patients. Int J Colorectal Dis 2011;26:183-90.

19. Yamato Y, Koike T, Yoshiya K, et al. Factors influencing long-term survival and surgical indications for pulmonary metastasectomy for metastases from colorectal cancer. Thorac Cancer 2011;2:95-100.

20. Pfannschmidt J, Muley T, Hoffmann H, et al. Prognostic factors and survival after complete resection of pulmonary metastases from colorectal carcinoma: experiences in 167 patients. J Thorac Cardiovasc Surg 2003;126:732-9.

21. Kim CH, Huh JW, Kim HJ, et al. Factors influencing oncological outcomes in patients who develop pulmonary metastases after curative resection of colorectal cancer. Dis Colon Rectum 2012;55:459-64.

22. Iizasa T, Suzuki M, Yoshida S, et al. Prediction of prognosis and surgical indications for pulmonary metastasectomy from colorectal cancer. Ann Thorac Surg 2006;82:254-60.

23. Chen F, Hanaoka N, Sato K, et al. Prognostic factors of pulmonary metastasectomy for colorectal carcinomas. World J Surg 2009;33:505-11.

24. Salah S, Watanabe K, Welter S, et al. Colorectal cancer pulmonary oligometastases: pooled analysis and construction of a clinical lung metastasectomy prognostic model. Ann Oncol 2012;23:2649-55.

25. Le UT, Bronsert P, Picardo F, et al. Intraoperative detection of circulating tumor cells in pulmonary venous blood during metastasectomy for colorectal lung metastases. Sci Rep 2018;8:8751.

26. Hashimoto M, Tanaka F, Yoneda K, et al. The clinical value of circulating tumour cells (CTCs) in patients undergoing pulmonary metastasectomy for metastatic colorectal cancer. J Thorac Dis 2018;10:1569-77.

27. Corsini EM, Mitchell KG, Correa A, et al. Effect of primary colorectal cancer tumor location on survival after pulmonary metastasectomy. J Thorac Cardiovasc Surg 2021;162:296-305.

28. Sponholz S, Oguzhan S, Mese M, et al. The impact of primary tumor location on prognosis after colorectal lung metastasectomy. Int J Colorectal Dis 2021;36:1731-7.

29. Zabaleta J, Iida T, Falcoz PE, et al. Individual data meta-analysis for the study of survival after pulmonary metastasectomy in colorectal cancer patients: A history of resected liver metastases worsens the prognosis. Eur J Surg Oncol 2018;44:1006-12.

30. Hattori N, Kanemitsu Y, Komori K, et al. Outcomes after hepatic and pulmonary metastasectomies compared with pulmonary metastasectomy alone in patients with colorectal cancer metastasis to liver and lungs. World J Surg 2013;37:1315-21.

31. Zabaleta J, Aguinagalde B, Fuentes MG, et al. Survival after lung metastasectomy for colorectal cancer: importance of previous liver metastasis as a prognostic factor. Eur J Surg Oncol 2011;37:786-90.

32. Landes U, Robert J, Perneger T, et al. Predicting survival after pulmonary metastasectomy for colorectal cancer: previous liver metastases matter. BMC Surg 2010;10:17.

33. Regnard JF, Grunenwald D, Spaggiari L, et al. Surgical treatment of hepatic and pulmonary metastases from colorectal cancers. Ann Thorac Surg 1998;66:214-8; discussion 218-9.

34. Robinson BJ, Rice TW, Strong SA, et al. Is resection of pulmonary and hepatic metastases warranted in patients with colorectal cancer? J Thorac Cardiovasc Surg 1999;117:66-75; discussion 75-6.

35. Headrick JR, Miller DL, Nagorney DM, et al. Surgical treatment of hepatic and pulmonary metastases from colon cancer. Ann Thorac Surg 2001;71:975-9; discussion 979-80.

36. Labow DM, Buell JE, Yoshida A, et al. Isolated pulmonary recurrence after resection of colorectal hepatic metastases-is resection indicated? Cancer J 2002;8:342-7.

37. Yamada H, Katoh H, Kondo S, et al. Surgical treatment of pulmonary recurrence after hepatectomy for colorectal liver metastases. Hepatogastroenterology 2002;49:976-9.

38. Patel NA, Keenan RJ, Medich DS, et al. The presence of colorectal hepatic metastases does not preclude pulmonary metastasectomy. Am Surg 2003;69:1047-53; discussion 1053.

39. Reddy RH, Kumar B, Shah R, et al. Staged pulmonary and hepatic metastasectomy in colorectal cancer--is it worth it? Eur J Cardiothorac Surg 2004;25:151-4.

40. Zizzo M, Galeone C, Braglia L, et al. Long-Term Outcomes after Surgical Resection for Synchronous or Metachronous Hepatic and Pulmonary Colorectal Cancer Metastases. Digestion 2020;101:144-55.

41. Matsumura M, Yamashita S, Ishizawa T, et al. Oncological 
benefit of complete metastasectomy for simultaneous colorectal liver and lung metastases. Am J Surg 2020;219:80-7.

42. Reijonen P, Kivelä A, Rantonen J, et al. Long-term outcome after sequential liver and lung metastasectomy is comparable to outcome of isolated liver or lung metastasectomy in colorectal carcinoma. Surg Oncol 2019;30:22-6.

43. Tsukamoto S, Kinugasa Y, Yamaguchi T, et al. Survival after resection of liver and lung colorectal metastases in the era of modern multidisciplinary therapy. Int J Colorectal Dis 2014;29:81-7.

44. Kamiyoshihara M, Igai H, Kawatani N, et al. Lung metastasectomy for postoperative colorectal cancer in patients with a history of hepatic metastasis. Gen Thorac Cardiovasc Surg 2014;62:314-20.

45. Limmer S, Oevermann E, Killaitis C, et al. Sequential surgical resection of hepatic and pulmonary metastases from colorectal cancer. Langenbecks Arch Surg 2010;395:1129-38.

46. Marudanayagam R, Ramkumar K, Shanmugam V, et al. Long-term outcome after sequential resections of liver and lung metastases from colorectal carcinoma. HPB (Oxford) 2009;11:671-6.

47. Lee WS, Yun HR, Yun SH, et al. Treatment outcomes of hepatic and pulmonary metastases from colorectal carcinoma. J Gastroenterol Hepatol 2008;23:e367-72.

48. Corsini EM, Mitchell KG, Mehran RJ, et al. Colorectal cancer mutations are associated with survival and recurrence after pulmonary metastasectomy. J Surg Oncol 2019;120:729-35.

49. Ghidini M, Personeni N, Bozzarelli S, et al. KRAS mutation in lung metastases from colorectal cancer: prognostic implications. Cancer Med 2016;5:256-64.

50. Schweiger T, Hegedüs B, Nikolowsky C, et al. EGFR, BRAF and KRAS status in patients undergoing pulmonary metastasectomy from primary colorectal carcinoma: a prospective follow-up study. Ann Surg Oncol 2014;21:946-54.

51. Vidarsdottir H, Siesing C, Nodin B, et al. Clinical significance of RBM3 expression in surgically treated colorectal lung metastases and paired primary tumors. J Surg Oncol 2021;123:1144-56.

52. Chen F, Sakai H, Miyahara R, et al. Repeat resection of pulmonary metastasis is beneficial for patients with colorectal carcinoma. World J Surg 2010;34:2373-8.

53. Park JS, Kim HK, Choi YS, et al. Outcomes after repeated resection for recurrent pulmonary metastases from colorectal cancer. Ann Oncol 2010;21:1285-9.

54. Bellier J, De Wolf J, Hebbar M, et al. Repeated Resections of Hepatic and Pulmonary Metastases from Colorectal Cancer Provide Long-Term Survival. World J Surg 2018;42:1171-9.

55. Menna C, Berardi G, Tierno SM, et al. Do Repeated Operations for Recurrent Colorectal Lung Metastases Result in Improved Survival? Ann Thorac Surg 2018;106:421-7.

56. Welter S, Jacobs J, Krbek T, et al. Long-term survival after repeated resection of pulmonary metastases from colorectal cancer. Ann Thorac Surg 2007;84:203-10.

57. Blackmon SH, Stephens EH, Correa AM, et al. Predictors of recurrent pulmonary metastases and survival after pulmonary metastasectomy for colorectal cancer. Ann Thorac Surg 2012;94:1802-9.

58. Salah S, Watanabe K, Park JS, et al. Repeated resection of colorectal cancer pulmonary oligometastases: pooled analysis and prognostic assessment. Ann Surg Oncol 2013;20:1955-61.

59. Hishida T, Tsuboi M, Okumura T, et al. Does Repeated Lung Resection Provide Long-Term Survival for Recurrent Pulmonary Metastases of Colorectal Cancer? Results of a Retrospective Japanese Multicenter Study. Ann Thorac Surg 2017;103:399-405.

60. Sponholz S, Schirren M, Baldes N, et al. Repeat resection for recurrent pulmonary metastasis of colorectal cancer. Langenbecks Arch Surg 2017;402:77-85.

61. Fukada M, Matsuhashi N, Takahashi T, et al. Prognostic factors in pulmonary metastasectomy and efficacy of repeat pulmonary metastasectomy from colorectal cancer. World J Surg Oncol 2020;18:314.

62. Nakajima J, Iida T, Okumura S, et al. Recent improvement of survival prognosis after pulmonary metastasectomy and advanced chemotherapy for patients with colorectal cancer. Eur J Cardiothorac Surg 2017;51:869-73.

63. Zhang GQ, Taylor JP, Stem M, et al. Aggressive Multimodal Treatment and Metastatic Colorectal Cancer Survival. J Am Coll Surg 2020;230:689-98.

64. Hawkes EA, Ladas G, Cunningham D, et al. Perioperative chemotherapy in the management of resectable colorectal cancer pulmonary metastases. BMC Cancer 2012;12:326.

65. Brandi G, Derenzini E, Falcone A, et al. Adjuvant systemic chemotherapy after putative curative resection of colorectal liver and lung metastases. Clin Colorectal Cancer 2013;12:188-94.

66. Shiomi K, Naito M, Sato T, et al. Effect of adjuvant 
chemotherapy after pulmonary metastasectomy on the prognosis of colorectal cancer. Ann Med Surg (Lond) 2017;20:19-25.

67. Subbiah IM, Blackmon SH, Correa AM, et al. Preoperative chemotherapy prior to pulmonary metastasectomy in surgically resected primary colorectal carcinoma. Oncotarget 2014;5:6584-93.

68. Rapicetta C, Lococo F, Davini F, et al. Is Adjuvant Chemotherapy Worthwhile After Radical Resection for Single Lung Metastasis From Colorectal Cancer? A Multicentric Analysis Evaluating the Risk of Recurrence. Front Oncol 2019;9:763.

69. Cerfolio RJ, McCarty T, Bryant AS. Non-imaged pulmonary nodules discovered during thoracotomy for metastasectomy by lung palpation. Eur J Cardiothorac Surg 2009;35:786-91; discussion 791.

70. Eckardt J, Licht PB. Thoracoscopic versus open pulmonary metastasectomy: a prospective, sequentially controlled study. Chest 2012;142:1598-602.

71. Cerfolio RJ, Bryant AS, McCarty TP, et al. A prospective study to determine the incidence of non-imaged malignant pulmonary nodules in patients who undergo metastasectomy by thoracotomy with lung palpation. Ann Thorac Surg 2011;91:1696-700; discussion 1700-1.

72. Prenafeta Claramunt N, Hwang D, de Perrot M, et al. Incidence of Ipsilateral Side Recurrence After Open or Video-Assisted Thoracic Surgery Resection of Colorectal Lung Metastases. Ann Thorac Surg 2020;109:1591-7.

73. Murakawa T, Sato H, Okumura S, et al. Thoracoscopic surgery versus open surgery for lung metastases of colorectal cancer: a multi-institutional retrospective analysis using propensity score adjustment†. Eur J Cardiothorac Surg 2017;51:1157-63.

74. Meng D, Fu L, Wang L, et al. Video-assisted thoracoscopic surgery versus open thoracotomy in pulmonary metastasectomy: a meta-analysis of observational studies. Interact Cardiovasc Thorac Surg 2016;22:200-6.

75. Hou Z, Zhang H, Gui L, et al. Video-assisted thoracoscopic surgery versus open resection of lung metastases from colorectal cancer. Int J Clin Exp Med 2015;8:13571-7.

76. Carballo M, Maish MS, Jaroszewski DE, et al. Videoassisted thoracic surgery (VATS) as a safe alternative for the resection of pulmonary metastases: a retrospective cohort study. J Cardiothorac Surg 2009;4:13.

77. Nakajima J, Murakawa T, Fukami T, et al. Is thoracoscopic surgery justified to treat pulmonary metastasis from colorectal cancer? Interact Cardiovasc Thorac Surg
2008;7:212-6; discussion 216-7.

78. De Bellis M, Vega EA, Kawaguchi Y, et al. Simultaneous Sigmoid Colectomy, Bilobar Liver Resection and Lung Metastasectomy via a Transdiaphragmatic Approach for Stage IV Colonic Adenocarcinoma. Ann Surg Oncol 2021;28:863-4.

79. Delis SG, Madariaga J, Bakoyiannis A, et al. Combined liver and lung metastasectomy through an exclusive transthoracic approach. J Surg Oncol 2007;96:178-82.

80. Mise Y, Mehran RJ, Aloia TA, et al. Simultaneous lung resection via a transdiaphragmatic approach in patients undergoing liver resection for synchronous liver and lung metastases. Surgery 2014;156:1197-203.

81. Nelson DB, Tayob N, Mitchell KG, et al. Surgical margins and risk of local recurrence after wedge resection of colorectal pulmonary metastases. J Thorac Cardiovasc Surg 2019;157:1648-55.

82. Welter S, Theegarten D, Trarbach T, et al. Safety distance in the resection of colorectal lung metastases: a prospective evaluation of satellite tumor cells with immunohistochemistry. J Thorac Cardiovasc Surg 2011;141:1218-22.

83. Ike H, Shimada H, Ohki S, et al. Results of aggressive resection of lung metastases from colorectal carcinoma detected by intensive follow-up. Dis Colon Rectum 2002;45:468-73; discussion 473-5.

84. Rotolo N, De Monte L, Imperatori A, et al. Pulmonary resections of single metastases from colorectal cancer. Surg Oncol 2007;16 Suppl 1:S141-4.

85. Matsutani N, Okumura S, Yoshino I, et al. Pneumonectomy in pulmonary metastasis. J Thorac Dis 2017;9:4523-30.

86. Imperatori A, Rotolo N, Dominioni L, et al. Durable recurrence-free survival after pneumonectomy for late lung metastasis from rectal cancer: case report with genetic and epigenetic analyses. BMC Cancer 2015;15:567.

87. Handy JR, Bremner RM, Crocenzi TS, et al. Expert Consensus Document on Pulmonary Metastasectomy. Ann Thorac Surg 2019;107:631-49.

88. Kirschbaum A, Braun S, Rexin P, et al. Comparison of local tissue damage: monopolar cutter versus Nd:YAG laser for lung parenchyma resection. An experimental study. Interact Cardiovasc Thorac Surg 2014;18:1-6.

89. Moneke I, Funcke F, Schmid S, et al. Pulmonary laserassisted metastasectomy is associated with prolonged survival in patients with colorectal cancer. J Thorac Dis 2019;11:3241-9.

90. Renaud S, Seitlinger J, Lawati YA, et al. Anatomical 
Resections Improve Survival Following Lung Metastasectomy of Colorectal Cancer Harboring KRAS Mutations. Ann Surg 2019;270:1170-7.

91. Igarashi T, Shimizu K, Usui K, et al. Significance of RAS mutations in pulmonary metastases of patients with colorectal cancer. Int J Clin Oncol 2020;25:641-50.

92. Pfannschmidt J, Klode J, Muley T, et al. Nodal involvement at the time of pulmonary metastasectomy: experiences in 245 patients. Ann Thorac Surg 2006;81:448-54.

93. Welter S, Jacobs J, Krbek T, et al. Prognostic impact of lymph node involvement in pulmonary metastases from colorectal cancer. Eur J Cardiothorac Surg 2007;31:167-72.

94. Szöke T, Kortner A, Neu R, et al. Is the mediastinal lymphadenectomy during pulmonary metastasectomy of colorectal cancer necessary? Interact Cardiovasc Thorac Surg 2010;10:694-8.

95. Hamaji M, Cassivi SD, Shen KR, et al. Is lymph node dissection required in pulmonary metastasectomy for colorectal adenocarcinoma? Ann Thorac Surg 2012;94:1796-800.

96. Renaud S, Alifano M, Falcoz PE, et al. Does nodal status influence survival? Results of a 19-year systematic lymphadenectomy experience during lung metastasectomy of colorectal cancer. Interact Cardiovasc Thorac Surg 2014;18:482-7.

97. Hiraki T, Gobara H, Iguchi T, et al. Radiofrequency ablation as treatment for pulmonary metastasis of colorectal cancer. World J Gastroenterol 2014;20:988-96.

98. Carrafiello G, Mangini M, Fontana F, et al. Complications of microwave and radiofrequency lung ablation: personal experience and review of the literature. Radiol Med 2012;117:201-13.

99. Chua TC, Sarkar A, Saxena A, et al. Long-term outcome of image-guided percutaneous radiofrequency ablation of lung metastases: an open-labeled prospective trial of 148 patients. Ann Oncol 2010;21:2017-22.

100. Palussière J, Canella M, Cornelis F, et al. Retrospective review of thoracic neural damage during lung ablation what the interventional radiologist needs to know about neural thoracic anatomy. Cardiovasc Intervent Radiol 2013;36:1602-13.

doi: 10.21037/asj-21-59

Cite this article as: Mak KL, Hsin MKY. Lung metastases from colorectal cancer: a multidisciplinary approach and role of local treatment: a narrative review. AME Surg J 2022;2:23.
101. Binkley MS, Trakul N, Jacobs LR, et al. Colorectal Histology Is Associated With an Increased Risk of Local Failure in Lung Metastases Treated With Stereotactic Ablative Radiation Therapy. Int J Radiat Oncol Biol Phys 2015;92:1044-52.

102. Choi HS, Jeong BK, Kang KM, et al. Tumor Control and Overall Survival after Stereotactic Body Radiotherapy for Pulmonary Oligometastases from Colorectal Cancer: A Meta-Analysis. Cancer Res Treat 2020;52:1188-98.

103.Agolli L, Bracci S, Nicosia L, et al. Lung Metastases Treated With Stereotactic Ablative Radiation Therapy in Oligometastatic Colorectal Cancer Patients: Outcomes and Prognostic Factors After Long-Term Follow-Up. Clin Colorectal Cancer 2017;16:58-64.

104. Carvajal C, Navarro-Martin A, Cacicedo J, et al. Stereotactic body radiotherapy for colorectal lung oligometastases: preliminary single-institution results. J BUON 2015;20:158-65.

105. Filippi AR, Badellino S, Ceccarelli M, et al. Stereotactic ablative radiation therapy as first local therapy for lung oligometastases from colorectal cancer: a single-institution cohort study. Int J Radiat Oncol Biol Phys 2015;91:524-9.

106. Nelson DB, Tayob N, Nguyen QN, et al. Local failure after stereotactic body radiation therapy or wedge resection for colorectal pulmonary metastases. J Thorac Cardiovasc Surg 2019;158:1234-1241.e16.

107.Song Y, Bruce AN, Fraker DL, et al. Isolated limb perfusion and infusion in the treatment of melanoma and soft tissue sarcoma in the era of modern systemic therapies. J Surg Oncol 2019;120:540-9.

108. den Hengst WA, Hendriks JM, Balduyck B, et al. Phase II multicenter clinical trial of pulmonary metastasectomy and isolated lung perfusion with melphalan in patients with resectable lung metastases. J Thorac Oncol 2014;9:1547-53.

109. Beckers PAJ, Versteegh MIM, Van Brakel TJ, et al. Multicenter Phase II Clinical Trial of Isolated Lung Perfusion in Patients With Lung Metastases. Ann Thorac Surg 2019;108:167-74.

110. Ramadan K, Gomes B, Pipkin M, et al. A model to assess acute and delayed lung toxicity of oxaliplatin during in vivo lung perfusion. J Thorac Cardiovasc Surg 2021;161:1626-35. 